\title{
The Case for Differentiated Professional Support: Toward a Phase Theory of Teacher Development
}

\author{
Rachael E. Gabriel \\ University of Tennessee, Knoxville
}

\begin{abstract}
In this perspective article I draw upon interviews with first-, second-, and third-year teachers to develop a phase theory of professional development that accounts for the questions, interests, and preferences of teachers across their first three years in the classroom. I suggest that differentiated professional development has the potential to improve the quality of the teaching force by increasing the expertise of teachers in their first few years and providing support that is engaging and rewarding enough to encourage retention.
\end{abstract}

\section{Equal Treatment}

Thomas Jefferson once said, "There is nothing more unequal as the equal treatment of unequal people." Applied to education settings, teachers in a single school have widely varying degrees of experience, professional interests, and levels of competence and commitment; yet most attend the same professional development programs whether they are high-performing or low-performing, expert or novice, committed or not, competent or not. A one-size-fits-all approach to professional development inherently ensures that some teachers on staff are not engaged, challenged, or supported enough to be working at their full potential. In this paper I draw upon interviews with first, second, and third year teachers to develop a phase theory of professional development that accounts for the questions, interests, and preferences of teachers across their first three years in the classroom.

I argue that just like effective instruction for students, effective professional development (PD) should be differentiated in order to be responsive to the needs, interests, awareness, and commitment of individual teachers. Some districts address the need to differentiate PD by providing an extensive menu of options from which teachers can choose. Though this may work for teachers who are highly committed and keenly aware of their individual areas for growth, it does not support those who are less committed or less aware of the elements at play in developing expertise. Selecting PD from a long menu of options also risks fragmented or incoherent experiences for teachers instead of collaborative engagement in a coherent, ongoing process of development. Extensive menus of options and one-size-fits-all inservice presentations both have design flaws that make the goal of each teacher developing competence and developing or maintaining his or her commitment to the field difficult. In order to provide 
a set of PD options that are relevant and coherent for beginning teachers, it is important to consider common patterns of needs and interests among teachers and how these may change or develop over time.

\section{Toward a Phase Theory of Professional Growth}

Is there a pattern to the needs and interests of beginning teachers? Is a first-year teacher's profile the same as that of a second-year teacher? Is a second year teacher's profile the same as that of a veteran? If they are different in their strengths, needs, and interests, should they be supported the same way? These were the questions that guided this study of beginning teachers' perceptions of the professional development they received. I chose to study alternatively certified teachers for two reasons: (a) the importance of on-the-job learning for teachers without extensive preservice preparation and (b) the growing number and presence of alternatively certified teachers in highneed schools (Feistritzer, 2009). In writing for the National Center for Educational Information (NCEI) Feistritzer admits there is a range of programs labeled alternative routes to teaching, but notes, "Sophisticated and well-designed programs that address the professional preparation needs of the growing population of individuals who already have at least a bachelor's degree and considerable life experience and want to become teachers are becoming the norm" (Feistritzer, "Background", para. 3). Though it is difficult to explicitly define alternative certification, NCEI estimates that approximately 62,000 alternatively certified teachers were hired for the 2007-2008 school year, representing almost a third of all new teachers (Feistritzer).

In the course of analyzing teacher interviews and reviewing the literature on professional development and adult learning, I have begun to sketch a trajectory of professional growth for beginning teachers, which could be used to inform the selection and design of differentiated professional support. Teachers and educational researchers have long agreed that one-size-fits-all models of professional development are dangerously ineffective in terms of building teacher capacity and engagement in professional learning (Darling-Hammond \& Richardson, 2009; Garet, Porter, Desimone, Birman, \& Yoon, 2001). Inservice trainings, where the same information is presented the same way to all teachers regardless of their experience, interest, or areas for growth, have been criticized over and over again in teacher education research and surveys of teachers' opinions. Differentiated professional growth opportunities may, on the other hand, provide the timely, specific, engaging opportunities for professional learning that beginning teachers need in order to experience greater success, satisfaction, and engagement in their professional learning during the years when attrition rates are highest.

In this study, I invited two first-, two second-, and two third-year teachers from a single school to share their perceptions of the opportunities for professional growth available at school, within the university master's degree program in which they were all enrolled, and from an outside nonprofit organization. I used a semi-structured interview 
protocol to guide each of the six interviews, which lasted between 50 and 90 minutes. In each case, teachers volunteered more information and anecdotes for at least 15 minutes after I thanked them for answering the last question. These teachers all taught different middle school grade levels and subjects. I analyzed teacher interviews and relevant research working with the assumption that teacher learning can be transformative - that new knowledge can integrate with old knowledge instead of piling on top of it-and that it will be most meaningful when teachers are actively engaged in what they are learning. Adult learning theories and theories of human motivation say that such engagement comes, in part, from matching support with individual teachers' interests and goals for growth (Mezirow, 2000; Ryan \& Deci, 1985).

Based on a thematic analysis of teachers' interviews (Merriam, 1998), I suggest that there are predictable phases in a common trajectory of professional growth in beginning teachers (See Table 1). A developmentally appropriate sequence of coursework and professional growth opportunities would support teacher learning within an appropriate zone of proximal development (Vygotsky, 1978) by tailoring support to the teacher's individual phase of professional growth. This phase theory of professional development could inform the content and nature of differentiated school-, district-, and university-based professional growth opportunities.

Table 1

Phases of Professional Growth

\begin{tabular}{cccc}
\hline Phase & $\begin{array}{c}\text { Phase 1: Technical } \\
\text { Assistance }\end{array}$ & $\begin{array}{c}\text { Phase 2: Theory } \\
\text { Building }\end{array}$ & $\begin{array}{c}\text { Phase 3: } \\
\text { Sustenance }\end{array}$ \\
$\begin{array}{c}\text { Phase } \\
\text { description }\end{array}$ & $\begin{array}{c}\text { Becoming a teacher: } \\
\text { The mechanics of } \\
\text { teaching }\end{array}$ & $\begin{array}{c}\text { Becoming an educator: The art and science } \\
\text { of teaching }\end{array}$ & \\
\hline $\begin{array}{c}\text { Role of reflection } \\
\text { Reflect to solve } \\
\text { problems }\end{array}$ & $\begin{array}{c}\text { Reflect to find things } \\
\text { to improve }\end{array}$ & $\begin{array}{c}\text { Reflect to synthesize } \\
\text { new ideas with old } \\
\text { ideas }\end{array}$ \\
$\begin{array}{c}\text { Role of } \\
\text { colleagues }\end{array}$ & $\begin{array}{c}\text { Use colleagues for } \\
\text { help and answers }\end{array}$ & $\begin{array}{c}\text { Use colleagues as } \\
\text { reflection partners }\end{array}$ & $\begin{array}{c}\text { Use colleagues as } \\
\text { sources for new } \\
\text { ideas }\end{array}$
\end{tabular}




\begin{tabular}{|c|c|c|c|}
\hline \multirow{3}{*}{$\begin{array}{l}\text { Appropriate } \\
\text { support }\end{array}$} & Ways to collect & Reflection protocols & Inquiry/study groups \\
\hline & $\begin{array}{c}\text { Mini workshops on } \\
\text { tricks and fixes }\end{array}$ & $\begin{array}{l}\text { Longer workshops } \\
\text { on areas of } \\
\text { interest/need }\end{array}$ & Collaborative planning \\
\hline & $\begin{array}{l}\text { Extensive } \\
\text { observations } \\
\text { (frequent, with } \\
\text { actionable } \\
\text { feedback) }\end{array}$ & $\begin{array}{l}\text { Intensive } \\
\text { observations } \\
\text { (back to back } \\
\text { observations with } \\
\text { things to think } \\
\text { about) }\end{array}$ & \\
\hline \multirow[t]{2}{*}{$\begin{array}{l}\text { Relevant } \\
\text { coursework }\end{array}$} & $\begin{array}{l}\text { Methods } \\
\text { Classroom }\end{array}$ & $\begin{array}{l}\text { Theories about } \\
\text { learning and child } \\
\text { development }\end{array}$ & $\begin{array}{l}\text { Philosophies of } \\
\text { education }\end{array}$ \\
\hline & management & $\begin{array}{l}\text { Theoretical } \\
\text { frameworks }\end{array}$ & $\begin{array}{l}\text { Roles of the teacher } \\
\text { education policy } \\
\text { and school reform }\end{array}$ \\
\hline
\end{tabular}

\section{Phase 1: Technical Assistance}

The two first-year teachers in this study seemed to be in a technical, informationgathering phase in terms of their preferences for professional development, uses of collegial support, and purposes for reflection. Though they were each enrolled in graduate classes, had school and university-based mentors, and attended school-based inservice presentations, the two first-year teachers I interviewed cited a Saturday workshop series as the most useful form of professional development next to conversations with colleagues. This series allowed teachers to choose their workshops and work in content-specific groups with teachers across the district. The teachers consistently praised the workshops for providing choice, autonomy, and most importantly concrete resources such as resource packets, demonstrations, and handouts. This stood in sharp contrast to opinions about school-based inservice days and even graduate coursework, which were not designed to match their self-identified interests and areas for growth. These teachers expressed interest in observing different classrooms, collecting resources, seeing examples of units and assessment rubrics, and picking up the tricks and timesavers for classroom management and organization that would allow them to focus more on student learning. The availability of choice, concrete resources, and answers to their questions were the features of professional learning opportunities that first-year teachers valued the most.

All six participants ranked their colleagues as their most trusted and frequently used source of professional support. First-year teachers specifically described the use of colleagues as sources for answers or solutions to classroom problems. A first-year special education teacher said, "I'm surrounded by people who have had so much 
experience and they really have been my most reliable resource." This orientation towards collegial support is consistent with the information-gathering, technical phase of development in which they are most interested in concrete examples of what and how to teach. Like second- and third-year teachers, the first-year teachers also frequently mentioned reflection as a mechanism for professional growth. Their purposes for reflecting on their practice, however, were unique, and once again pointed to a more concrete and technical orientation. First-year teachers described reflection as a way to solve classroom problems that were apparent to them. A first-year teacher said, "I've been freaking out about co-teaching because it wasn't working out very well in one of my situations." A second-year teacher remembered:

Last year was kind of like... what's the word I'm looking for? Like damage control at every point... PD was always - I have this mess going on and I need a solution right now. And so like the most helpful things were always like just talking to other teachers.

They reflected in order to "fix" whatever first-year teachers noticed did not work. This focus on mechanics is descriptive of the first phase of development in terms of professional learning, collaboration, and reflection on practice.

First-year teacher narratives suggest that the professional growth opportunities that were most valued were those that offered concrete information, ideas, and resources that could be applied in classrooms immediately. Courses, workshops, and mentoring programs that did not address this focus were viewed as irrelevant, wasteful, and frustrating. Schools, districts, and university partners might consider providing resource exchanges, mentors focused on technical assistance, and courses that target methods and materials while teachers are focused on the what and how of teaching.

\section{Phase 2: Theory Building}

The second-year teachers I interviewed valued and used professional development programs, colleagues, and reflection differently than their first-year colleagues. They valued professional development opportunities that forced them to reflect on their teaching in new ways through new lenses. Similar to the first-year teachers, they valued colleagues and mentors who pushed them to see their classroom dynamics or teaching decisions differently. They especially valued those who guided their reflection and listened, rather than those who automatically provided answers. One second-year teacher discussed using the teacher next door as a sounding board to whom she could vent, rather than someone who had all the answers. Like the first-year teachers, they appreciated the choice and autonomy of the Saturday workshop series. However, they were no longer interested in broadly gathering tricks of the trade; rather, they valued the opportunity to tailor their professional learning to match their selfidentified areas for growth and inquiry. 
Teachers in this second phase reported reflecting on both micro and macro levels- in the moment during teaching and in retrospect. They no longer looked for ways to solve obvious problems because they realized obvious problems arise infrequently. One teacher discussed the transition to "looking for problems rather than being happy if a lesson seems to have gone well, like constantly looking for the gaps and making it better for the next one." Rather, the more subtle dynamics of classroom culture and instructional planning and delivery captured their attention. Both secondyear participants described being frustrated when outside observers failed to provide constructive criticism because areas for growth were less obvious to them. One participant's mentor teacher arranged several back-to-back observations in order to construct a more nuanced understanding of the teacher's work and therefore offered better feedback. This is a promising practice for teachers who still have much to learn but are not necessarily doing anything wrong.

Now that there were fewer fires to put out, teachers in the second phase began to wonder why the mechanics of teaching actually work, reflecting on the bigger picture of events in their classrooms. They wondered why students reacted the way they did, and why certain methods worked best for one group but not the next. One second-year teacher said she valued "anything that forces reflection" so that she could see new ways to improve. At this point in their development, teachers were becoming interested in the theory behind the methods with which they were beginning to have experience. They wanted to be able to identify the roots of surface issues they observed and to extend what they knew to new groups of students. They did not just seek answers to teaching problems; they wanted the reasons for the methods and the theory behind the ideas so that they could apply them flexibly with a sense of informed ownership. When asked what they thought PD should focus on, second-year teachers requested workshops on how to differentiate instruction based on student needs and learning styles and how to lead a grade-level team. First-year teachers asked for tips, materials, and ways to teach specific topics.

At this phase of a teacher's development, courses on educational psychology, theoretical foundations, and child development have potential to offer teachers the information they need to read student behavior and student progress with greater depth. Reflection protocols and opportunities to observe other teachers can likewise increase their ability to interpret and respond to their students. Teachers in the second phase of development valued their colleagues as thought partners, instead of answer-givers. Thus professional growth opportunities that focus on reflection and the development of a variety of lenses through which to examine instructional decisions and classroom dynamics are most valued and applicable during this phase.

\section{Phase 3: Sustenance}

When asked what kind of professional development she wished she had, one third-year teacher confessed, "I don't need any more resources. I have closets full of 
them... the best thing about my job is that I get to observe other teachers all day." As an inclusion teacher who pushes in to general education classrooms, this teacher explained, "The most helpful thing was just talking to other teachers or, you know even to other new teachers or whatever, and that was the fastest way of getting things done, which is why I do it." She reported being able to synthesize her observations from various classrooms and integrate those new ideas into her own style. Instead of gathering information, she gathered inspiration. Another third-year teacher agreed that the best part of her job was being able to observe and plan with other math teachers. Both teachers sought to engage in conversations with colleagues to build a sense of the bigger picture involved in educating children. They each reported voluntarily attending professional development opportunities (e.g., a teacher study group and a local teacher summit) in order to engage with a community of educators and build on their understanding of the implications and focus of their work. Their reflection was no longer focused on solving or identifying problems; rather, it focused on increasing their awareness and capacity to reach every student.

The third-year teachers in this study described their work in a broad context of district and national efforts to increase student achievement, as well as in a micro context of individual student interests, needs, and patterns of behavior. They seemed to be stretching and testing the boundaries of the methods and principles they accumulated by seeking new perspectives, examples, and ideas. Teaching, for teachers in this third phase, seemed to be redefined as a process with which to actively engage, rather than a task to execute and understand. They developed clearer and broader understandings of the implications of their work. They were therefore consistently looking for ways to stretch their current capacity to meet the needs and challenge for all of their students. Collaboration, observation, and professional inquiry seemed to best characterize teachers in this phase.

At this phase of a teacher's development, courses on educational philosophies, policies, and broader issues of social justice and public policy might (a) provide teachers the information they need to situate their experiences in a broader context and (b) help them align their instruction and responses to students with a broader philosophy. Workshops that encourage teachers to reconsider and re-envision their instruction (rather than trainings that dictate changes) and mentor or collegial relationships that allow collaboration and observation hold potential for being the most useful professional development opportunities for teachers in this phase.

\section{University Coursework} eyes."

"I told them they all had to do service learning projects and they rolled their

"I am teaching Piaget, and I know they need to know this, and they complain it has nothing to do with them." 
"I teach the foundations course, so I'm pretty unpopular around here."

These are statements I have heard university-based teacher educators make in the last year. Like missionaries bringing their versions of truth to the heathens, these professors wanted to bring a deeper understanding about teaching and learning to beginning teachers. They want students to view teaching as a craft, rather than a task. Unfortunately, sometimes the masses do not seem to want missionaries in the form of graduate school professors, or do they? The narratives of first-year teachers consistently described a common desire to understand both content and pedagogy more deeply. Questions centered on execution and organization of the tasks and processes of teaching. It was not, however, until the second year that participants expressed a desire to know why some methods and materials were not effective with their students. Perhaps they finally had the time and inclination to consider such things with a year of experiences, observations, and reflection under their belts or perhaps they had stopped collecting ideas and had moved toward considering what they had collected.

Third-year teachers continued to deepen their understanding of the reasons certain methods worked and also expressed interest in exploring the broader implications of their work with children. It may be that a course on philosophy of education or education policy is better suited to a teacher who has the mental space and practical context to engage with such content. Teachers who are consumed by the business of survival, integration into a new community, and first time trial and error in the classroom are logically less inclined to value or engage in theoretical inquiry. Contrary to the beliefs of some professors, however, the teachers I interviewed had an interest in and saw the importance of the content of their graduate classes at various points in their development. It may be that there is no perceived mismatch between the theory learned in university classrooms and actual practice in each teacher's classroom when theory is presented at an appropriate time.

Furthermore, perhaps there is no inherent theory-practice mismatch when theory is presented in an accessible context. Of all the Master of Arts classes these participants were enrolled in, the only one that received positive ratings was a content area reading course that included packets of sample materials, time in the beginning of each class to share teaching tips, and an action research project that focused on an instructional method teachers were already using. It allowed second-year teachers to discuss and reflect upon their practices using research and theory as a frame instead of as a separate addition to their planning or delivery. Thus even classes characterized by theoretical titles and syllabi can be brought down to earth in meaningful ways for beginning teachers by attaching the theory to issues and questions with which teachers are currently engaged. 
Thinking about theory on its own may take more mental space than many firstyear teachers have left over as they tentatively apply what they know, try, try again, and reflect on the outcomes of their teaching. Even the most talented, well-prepared firstyear teacher cannot think as deeply or broadly about teaching as someone who has been the instructional leader of a classroom over the full cycle of the school year. Once a teacher has entered the phase of wondering why instead of how to teach, theory and philosophy are not only relevant, but also critical to deepen reflection, knowledge, and perspective in the classroom.

\section{Conclusion}

Between limiting growth opportunities to one option and providing an extensive menu of possibilities from which teachers can select lies the possibility of tailoring professional growth options to common trends and patterns of needs and interests. When professional growth options are responsive to teachers' needs and interests, teacher engagement rises (Ryan \& Deci, 1985) and teacher learning is supported (Garet et al., 2001; Mezirow, 2000). I argue that this attention to engagement will build commitment to professional learning experiences and enhances the possibility that such experiences will actually work to increase teacher competence.

Effective, strategic support of beginning teachers is more urgent than ever simply because so many of the teachers charged with educating the neediest children are beginning teachers. Due to high attrition rates and teacher sorting (Lankford \& Loeb, 2002), children in high-need schools may have more beginning teachers than veteran teachers throughout their school careers (Feistritzer, 2009). Effective support of beginning teachers will therefore not only address teacher quality where it matters most, but also address teacher retention and job satisfaction where teacher turnover is highest. Providing differentiated professional development is thus a two-pronged approach to increasing the quality of the teaching force by increasing the expertise of a large subgroup of teachers (those in their first few years) and providing support that is engaging and rewarding enough to encourage retention.

\section{References}

Darling-Hammond, L., \& Richardson, N. (2009). Teacher learning: What matters? Educational Leadership, 66(5), 46-53.

Feistritzer, C. E. (2009). Alternative teacher certification: A state-by-state analysis 2009. Retrieved April 20, 2010 from http://www.ncei.com/Alt-Teacher-Cert.htm

Garet, M., Porter, A., Desimone, L., Birman, B., \& Yoon, K. (2001). What makes professional development effective? Results from a national sample of teachers. American Educational Research Journal, 38(4), 915-945. 
用 